\title{
A Single-Center, Case-Control Study of Low-Dose-Induction Oral Immunotherapy with Cow's Milk
}

\author{
Noriyuki Yanagida ${ }^{a}$ Sakura Sato $^{b}$ Tomoyuki Asaumi $^{a}$ Yu Okada ${ }^{a}$ \\ Kiyotake Ogura ${ }^{a}$ Motohiro Ebisawa ${ }^{\mathrm{b}}$ \\ ${ }^{a}$ Department of Pediatrics, Sagamihara National Hospital, and ${ }^{b}$ Clinical Research Center for Allergy and \\ Rheumatology, Sagamihara National Hospital, Kanagawa, Japan
}

\section{Key Words}

Milk $\cdot$ Immunotherapy $\cdot$ Desensitization $\cdot \operatorname{lgE} \cdot$ Tolerance .

Children · Anaphylaxis

\begin{abstract}
Background: This study aimed to investigate the efficacy and safety of low-dose-induction oral immunotherapy (OIT) with $3 \mathrm{ml}$ of milk, which is a lower target volume than is conventionally used. Methods: Children aged $\geq 5$ years with milk allergies [confirmed by oral food challenge (OFC) against $3 \mathrm{ml}$ of milk] were enrolled. The OIT group was admitted to the hospital for 5 days for build-up. Subsequently, at home, the volume was gradually increased by up to a maximum of $3 \mathrm{ml}$ every 5 days. While the OIT group ingested a small amount of milk every day, the control group completely eliminated their milk intake. Both groups underwent OFCs approximately 1 year later in order to assess their responsiveness to $3 \mathrm{ml}$ and $25 \mathrm{ml}$ of cow's milk. Results: The OIT and control groups had no background differences; the proportion of patients unresponsive to $3 \mathrm{ml}$ of milk after 1 year was $58.3 \%(7 / 12)$ and $13.8 \%(4 / 25)$, respectively $(p=0.018)$, while the proportion unresponsive to $25 \mathrm{ml}$ of milk was $33.3 \%$ $(4 / 12)$ and $0.0 \%(0 / 25)$, respectively $(p=0.007)$. Furthermore,
\end{abstract}

a significant decrease in the casein-specific immunoglobulin E levels was seen after 12 months when compared to baseline in the OIT group $(p=0.033)$. Adverse allergic reactions were rare and most symptoms were mild. Conclusion: This study of a high-risk population reacting to very low amounts of milk showed that low-dose-induction OIT appeared effective for acquiring unresponsiveness to $3 \mathrm{ml}$ and $25 \mathrm{ml}$ of milk, with severe symptoms being rare, indicating that for improvement of food allergies, continuous intake of small amounts may be as effective as intake of larger amounts.

(c) 2015 S. Karger AG, Basel

\section{Introduction}

Milk allergy is the most common food allergy in children [1-3]. Children with a reaction to small amounts of milk $(<10 \mathrm{ml})$, a past history of anaphylaxis to milk and high levels of milk-specific immunoglobulin E (IgE) are at a high risk of severe persistent milk allergy $[2,4-6]$. If the milk-specific IgE level is $>10 \mathrm{kUA} / \mathrm{l}$ before the age of 18 months, only $23 \%$ of such children are reportedly tolerant to milk at the age of 6 years [5].

\section{KARGER 125}

(c) 2015 S. Karger AG, Base

$1018-2438 / 15 / 1682-0131 \$ 39.50 / 0$

E-Mail karger@karger.com

www.karger.com/iaa
Correspondence to: Dr. Noriyuki Yanagida

Department of Pediatrics, Sagamihara National Hospital

18-1, Sakuradai, Minami-ku, Sagamihara

Kanagawa 252-0392 (Japan)

E-Mail n-yanagida@ sagamihara-hosp.gr.jp 
Oral immunotherapy (OIT) is becoming an increasingly common treatment for allergies $[7,8]$. The efficacy of OIT has been reported; however, the treatment performance of milk is particularly poor, the frequency of symptom induction is high and long-term therapy is required [7, 9-11]. Therefore, treatment methods with a higher level of safety are desired. Currently, many of the milk immunotherapies are set at a target volume of around 200 $\mathrm{ml}[7,10,12]$. However, with milk allergies, if a termination of elimination against approximately $3 \mathrm{ml}$ is possible, then $10 \mathrm{~g}$ of butter can be ingested, and a great improvement in quality of life may be possible [13].

Currently, there is no report on low-target-volume immunotherapy for food allergy, except for sublingual immunotherapy [14] and, although this is safer than OIT, it is less effective [15]. With this in mind, the aim of this study was to investigate the efficacy and safety of lowdose-induction OIT using $3 \mathrm{ml}$ of milk, i.e. a lower target volume than what is conventionally used.

\section{Materials and Methods}

Design

This study was a single-center, case-control study performed at the Sagamihara National Hospital between January 2013 and March 2015 (UMIN000011202).

Patients aged $\geq 5$ years, who had a history of anaphylaxis or high levels of milk-specific IgE ( $>50 \mathrm{kU} / \mathrm{ml})$, exhibited clearly positive symptoms [2] on the oral food challenge (OFC) against $3 \mathrm{ml}$ of milk and whose guardians had received an explanation of OIT, were divided into 2 groups: an OIT and a control group. The OIT group started OIT in August 2013 and the control group started after July 2014 according to the family's choice. In the OIT group, treatment was performed, but in the control group, no treatment was conducted. Two open OFCs against $3 \mathrm{ml}$ of milk were performed during the same period (online suppl. fig. 1; for all online suppl. material, see www.karger.com/doi/10.1159/000442157). To reduce the risk of bias, all cases within the designated period were included in the control group. In addition, the control group also started OIT after the second OFC (delayed-treatment control group design).

In both groups, cases where data on milk-specific IgE levels within 3 months of the OFC were lacking, cases lost to follow-up and cases with negative results in the first OFC were excluded.

\section{Oral Food Challenges}

For the OFC, we used pumpkin cakes containing $3 \mathrm{ml}$ of cow's milk (102 mg of milk protein), which were baked in a microwave oven $\left(1,000 \mathrm{~W}\right.$ for $1 \mathrm{~min} 30 \mathrm{~s}$ at a core temperature of $\left.89^{\circ} \mathrm{C}\right)$. We performed the OFC by administering the cake in 2 separate portions, as previously described [13], i.e. a quarter of the total dose was administered, and the rest of the cake $1 \mathrm{~h}$ later. The challenges were discontinued at the first objective sign of reaction. The symptoms provoked were assessed as outlined in online supplementary table 1 . The threshold volume was defined as the accumulated dose.

\section{Oral Immunotherapy}

The OIT group was admitted to the hospital for 5 days for build-up. On the first day, an open OFC was conducted using a pumpkin cake containing $3 \mathrm{ml}$ of milk masked by cocoa, and a confirmation was made as to whether objective symptoms occurred [2]. Oral administration of $10 \mathrm{mg}$ of loratadine was commenced on the night of the first day of admission. The same OFC was performed on the second day. On the third day, fresh milk, at half the threshold accumulated-volume dose of the OFC on the previous day, was administered twice daily at 2-hour intervals. If symptoms did not appear, double the volume was administered on the fourth day, and if symptoms did appear, the same volume was administered on the fourth day. On the fifth day, an OFC was performed using a single administration of the volume that could be consumed on the fourth day without symptoms. At home, the OIT group was encouraged to drink or ingest milk once a day. The volume was gradually increased by $0.1-0.5 \mathrm{ml}$ up to a maximum of $3 \mathrm{ml}$, every 5 days. Once $3 \mathrm{ml}$ was reached, oral administration of loratadine was ceased. The presence or absence of symptoms was assessed by keeping a diary. Approximately 1 year later, the subjects stopped the daily intake of milk for 2 weeks, and an open OFC was performed with $3 \mathrm{ml}$ of cow's milk. If this was negative, then an OFC was performed on the next day with $25 \mathrm{ml}$ of milk. Desensitization was defined as being able to consume $3 \mathrm{ml}$ without symptoms. Unresponsiveness was defined as a negative result in the OFC with $3 \mathrm{ml}$ of cow's milk after 2 weeks of complete elimination of milk from daily meals. We defined such patients as 'responders' while the rest of the patients were classified as 'nonresponders'.

\section{Follow-Up of the Control Group}

Patients in the control group were advised to completely eliminate milk until the next OFC. They received an open OFC with $3 \mathrm{ml}$ of cow's milk approximately 1 year later. If this was negative, then an OFC was performed on the next day with $25 \mathrm{ml}$ of milk. They did not receive any treatment during this period. After the second OFC, the control group started OIT.

\section{Evaluated Parameters}

The primary end point was the presence or absence of acquired unresponsiveness to $3 \mathrm{ml}$ of cow's milk after 1 year. Both groups underwent a pair of OFCs approximately 1 year apart to test their responsiveness. The secondary end point was the symptom induction rate of the OIT group.

\section{Immunological Parameters}

We used milk-, casein- and $\beta$-lactoglobulin-specific IgE levels (ImmunoCAPTM, Thermo Fisher Scientific, Mass., USA), measured within 6 months before the OFC for the control group and at $0,1,3,6$ and 12 months after the start of OIT for the OIT group, as prognostic markers [16].

\section{Statistical Analyses}

The results of the statistical analyses are expressed as the median value and range. For statistical comparisons between the 2 groups, we used the Mann-Whitney $U$ test, the paired Student $t$ test or the Fisher exact test, and p values $<0.05$ were considered statistically significant. The data were statistically analyzed using SPSS 20.0 software (IBM Corp., Armonk, N.Y., USA). 
Ethical Considerations

According to the Declaration of Helsinki, the study design and the risk of symptoms occurring with the OFC and the OIT were fully explained to the patients' guardians, both orally and in writing, and written informed consent was obtained for all participants. Personal details of the patients were separated from the results used in this study, and clinical data were deidentified as linked anonymized data. The study was approved by the Institutional Review Board of Sagamihara National Hospital.

\section{Results}

\section{Subject Background}

For the OIT group, OFCs using $3 \mathrm{ml}$ of cow's milk were performed for 13 candidates; of these, 1 negative case was excluded, resulting in 12 cases being included in our analysis. For the control group, no cases were excluded, resulting in 25 cases being analyzed (online suppl. table 2). In both groups, there were no dropouts after the commencement of treatment.

Both groups underwent an open OFC approximately 1 year after the first OFC (OIT group: 297-384 days, median 372 days; control group: 131-725 days, median 324 days). No difference was seen regarding the duration between the first OFC and the second OFC performed approximately 1 year later. There were 11/12 (91.7\%) and $18 / 25(72.0 \%)$ cases with a history of anaphylaxis in the OIT and control groups, respectively. There were no significant differences between groups regarding the background of the subjects.

\section{Unresponsiveness to 3 and 25 Milliliters of Milk}

The proportion of unresponsive subjects to $3 \mathrm{ml}$ of milk after 1 year was $58.3 \%(7 / 12)$ in the OIT group and $13.8 \%(4 / 25)$ in the control group ( $\mathrm{p}=0.031$; table 1$)$. The proportion of subjects desensitized to $3 \mathrm{ml}$ of milk was $66.7 \%(9 / 12)$ and $13.8 \%(4 / 25)$, respectively $(\mathrm{p}=0.001)$. Of the 7 desensitized and tolerant subjects in the OIT group, 4 subjects could consume as much as $25 \mathrm{ml}$, while symptoms were induced in 3 subjects. Thus, the proportion of unresponsive subjects to $25 \mathrm{ml}$ of milk was $33.3 \%$ $(4 / 12)$ and $0.0 \%(0 / 25)$ in the OIT and control groups, respectively $(\mathrm{p}=0.007)$.

\section{Immunological Parameters}

In the OIT group, compared to baseline, the milk-specific IgE levels showed a significant increase after 1 month $(\mathrm{p}=0.044)$, after which a significant decrease was observed, i.e. between 1 and 12 months ( $p=0.039$; fig. 1 ). The median milk-specific IgE levels at baseline and at 1
Table 1. Result of the second OFC 1 year later

\begin{tabular}{llll}
\hline & $\begin{array}{l}\text { Control group } \\
(\mathrm{n}=25)\end{array}$ & $\begin{array}{l}\text { OIT group } \\
(\mathrm{n}=12)\end{array}$ & $\begin{array}{l}\mathrm{p} \\
\text { value }\end{array}$ \\
\hline Desensitized to $3 \mathrm{ml}$ of milk & $4(13.8)$ & $9(75.0)$ & 0.001 \\
Unresponsive to $3 \mathrm{ml}$ of milk & $4(13.8)$ & $7(58.3)$ & 0.018 \\
Unresponsive to $25 \mathrm{ml}$ of milk & $0(0.0)$ & $4(33.3)$ & 0.007 \\
\hline
\end{tabular}

Values are presented as $\mathrm{n}(\%)$. Comparisons were made with Fisher's exact test. and 12 months were $38.2,53.8$ and $40.2 \mathrm{kUA} / \mathrm{l}$, respectively. On the other hand, while the casein-specific IgE levels did not significantly differ at baseline and after 1 month $(\mathrm{p}=0.099)$, a significant decrease was observed after 12 months $(\mathrm{p}=0.033)$. The median casein-specific IgE levels at baseline and at 1 and 12 months were 38.0, 43.2 and $30.6 \mathrm{kUA} / \mathrm{l}$, respectively. The $\beta$-lactoglobulinspecific IgE levels did not differ between any time points. The median serum levels of casein-specific IgG at baseline and after 1, 3, 6 and 12 months were 5.6, 12.8, 11.9, 10.0 and $10.0 \mathrm{mg} / \mathrm{l}$, respectively, with a significant difference observed only between baseline and at 1 month $(\mathrm{p}=$ 0.049; fig. 2). The median serum levels of casein-specific $\mathrm{IgG}_{4}$ at baseline and after 1, 3, 6 and 12 months were 0.5 , $0.9,0.7,0.9$ and $1.3 \mathrm{mg} / \mathrm{l}$, respectively, and significant differences were observed between baseline and at 1 month $(\mathrm{p}=0.026)$ and between baseline and at 3 months $(\mathrm{p}=$ 0.037; fig. 2).

In the control group, the milk-specific IgE levels did not show a difference between baseline and after 12 months ( $\mathrm{p}=0.722)$; the median levels were 38.5 and 37.6 $\mathrm{kUA} / \mathrm{l}$, respectively. The casein-specific IgE levels were measured in 21 cases and did not show a difference between baseline and after 12 months (median 33.0 and 33.0 $\mathrm{kUA} / \mathrm{l}$, respectively; $\mathrm{p}=0.278$ ). The $\beta$-lactoglobulinspecific IgE levels were measured in only 6 cases and so changes could therefore not be assessed in the control group.

In the OIT group, there were no significant differences in parameters or in the patients' background between responders and nonresponders, other than in the milkspecific IgE level at 6 months $(\mathrm{p}=0.030$; online suppl. table 3).

\section{Symptoms and Treatment}

The OIT group consumed milk a total of 56 times when admitted to the hospital and 3,739 times as outpa- 


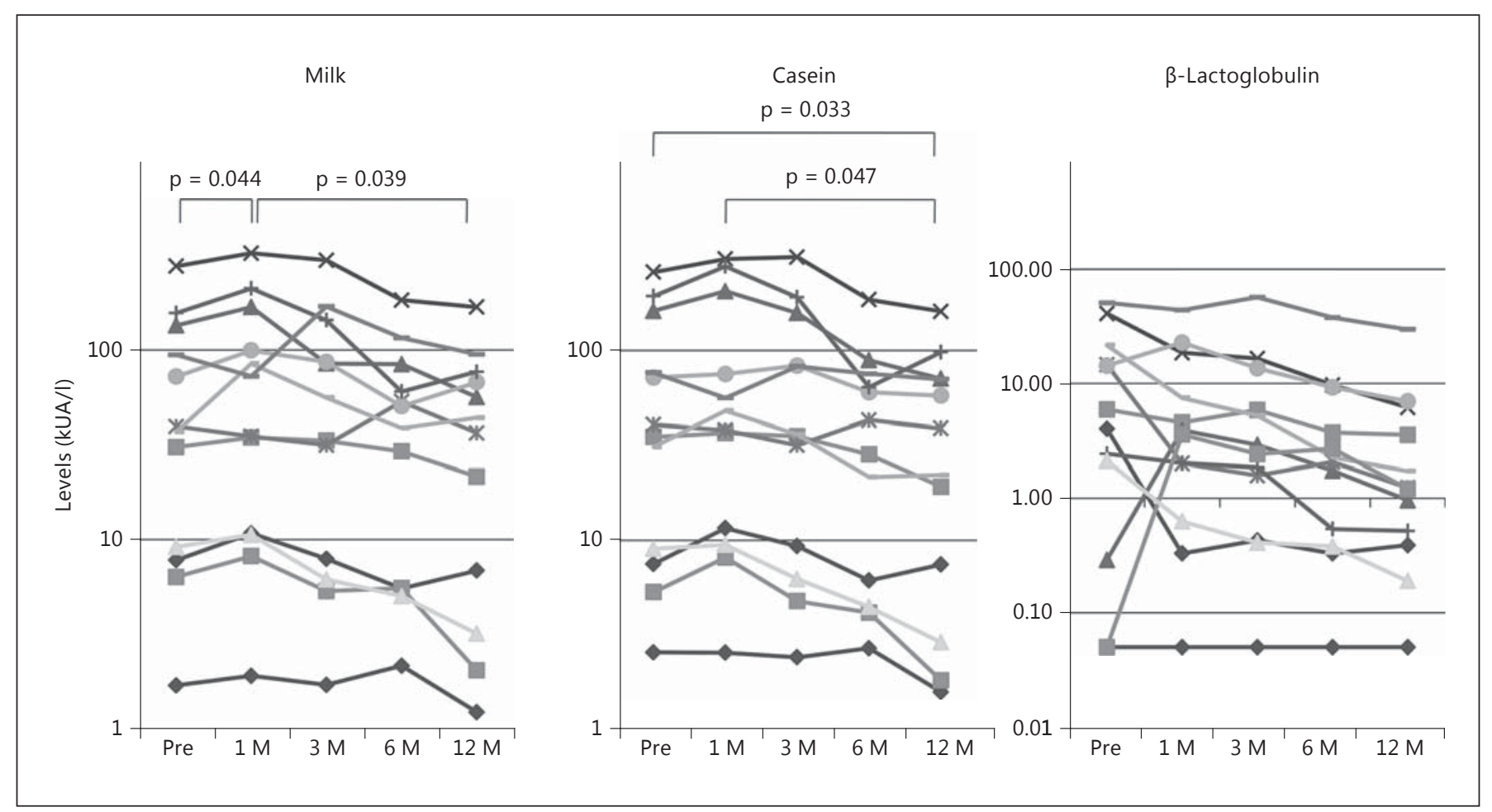

Fig. 1. Serum levels of antigen-specific IgE. Comparisons were made using the paired Student t test. Each line corresponds to 1 patient $(\mathrm{n}=12) . \mathrm{M}=\operatorname{Month}(\mathrm{s}) ;$ Pre = at baseline.

Fig. 2. Serum levels of casein-specific IgG and $\mathrm{IgG}_{4}$. Comparisons were made using the paired Student $t$ test. Each line corresponds to 1 patient $(n=12) . M=\operatorname{Month}(\mathrm{s})$; Pre $=$ at baseline .

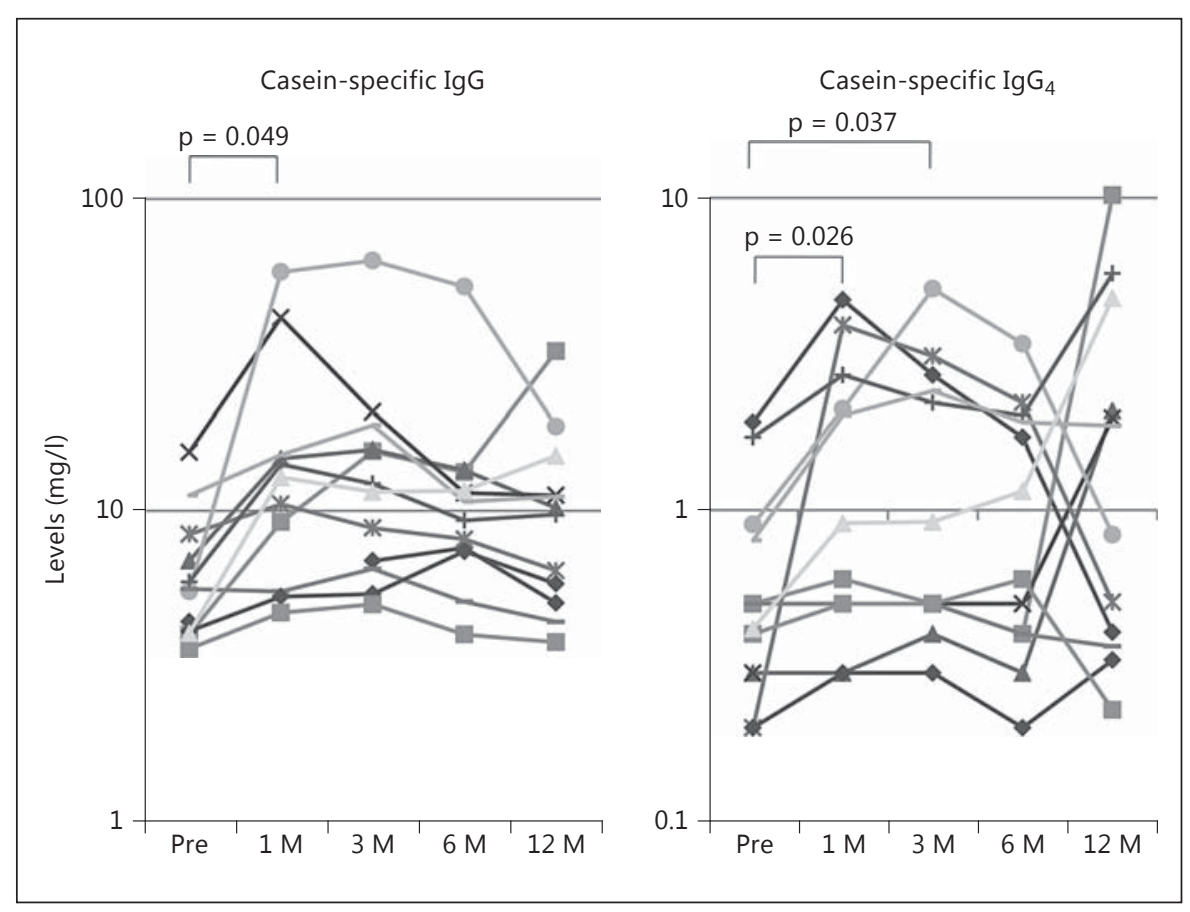


Table 2. Adverse allergic reactions during the OIT protocol

\begin{tabular}{lcc}
\hline & In hospital & At home \\
\hline Total number of intakes of OIT & 56 & 3,739 \\
Adverse reactions, n (\%) & $32(57.1)$ & $729(19.5)$ \\
$\quad$ Mild & $13(23.2)$ & $656(17.5)$ \\
$\quad$ Moderate & $11(19.6)$ & $73(2.0)$ \\
$\quad$ Severe & $0(0.0)$ & $1(0.03)$ \\
Symptoms, n (\%) & & \\
Mucosal & $24(42.9)$ & $485(13.0)$ \\
Gastrointestinal & $3(5.3)$ & $157(4.2)$ \\
Skin & $2(3.6)$ & $31(0.8)$ \\
Respiratory & $11(19.6)$ & $162(4.3)$ \\
Cardiovascular & $0(0.0)$ & $0(0.0)$ \\
Neurological & $0(0.0)$ & $6(0.2)$ \\
\hline
\end{tabular}

tients (table 2). The symptom induction rate per intake was $57.1 \%$ in the hospital and $19.5 \%$ at home. Mild symptoms represented 23.2 and $17.5 \%$ of the hospital and athome cases, moderate symptoms 19.6 and $2.0 \%$ and severe symptoms 0 and $0.03 \%$, respectively. Both in the hospital and at home, the majority of symptoms were oral mucosal symptoms. At home, most symptoms were mild, and all neurological symptoms were symptoms such as 'feeling unwell'. Medication was administered for 21.4 and $2.3 \%$ of cases in the hospital and at home, respectively, with antihistamines being the most common treatment (online suppl. table 4). In 1 case, where $2.5 \mathrm{ml}$ of milk was consumed at home and the patient developed a cough, a medical examination was conducted at a hospital not specializing in allergies, and although symptoms were not present at the time of examination, adrenaline was administered.

\section{Discussion}

\section{Milk Allergy and Oral Immunotherapy}

Milk allergy is the most common food allergy in children [1-3]. However, many children tend to outgrow food allergies that occur at 6 years, at the end of childhood in half of all cases (based on the natural history of milk allergy) and by their teenage years in approximately $80 \%$ of cases [17]. Nevertheless, some children continue to have food allergies beyond their teenage years, and complete elimination of milk may lead to complications such as shorter body height [18-20]. Previously, the best approach was considered to be the complete avoidance of milk and milk products and repeating OFCs until the re- sult became negative. We performed low-dose-induction OIT in high-risk subjects with a history of severe symptoms (anaphylaxis; 91.7\%), high milk-specific IgE levels and who had previously reacted to $\leq 3 \mathrm{ml}$ of milk (i.e. very low amounts). One previous study reported that such high-risk patients rarely tolerate milk [21]. For OIT, clinically significant factors for achieving full tolerance to cow's milk protein have been reported to be a higher starting dose [odds ratio (OR) 4.6 (for $30 \mathrm{mg}$ )], not requiring epinephrine during induction (OR 5.2), and lack of non-anaphylactic reactions (OR 15.6) [22, 23].

The efficacy of OIT has been previously reported [7, 8]. However, the treatment performance of milk has been particularly poor, the frequency of symptom induction is high and long-term therapy is required [7, 9-11]. Treatment methods with a higher level of safety are desirable.

\section{Low Target Volume}

The main point of this study is that the target volume was very low: $3 \mathrm{ml}$ of cow's milk. If a termination of elimination against approximately $3 \mathrm{ml}$ is possible, then $10 \mathrm{~g}$ of butter can consequently be ingested, and a large improvement in quality of life may be possible [13]. Moreover, as a result, accidental exposure to small amounts of milk products is also expected not to produce symptoms, and this can further improve the quality of life of the subjects by reducing the fear of severe symptoms upon accidental ingestion.

Regarding the unresponsiveness to $3 \mathrm{ml}$ of cow's milk after 1 year, a significant difference was observed in the OIT group compared to in the control group, indicating that low levels of intake may be effective in acquiring tolerance. Seven of the 12 patients in the OIT group tolerated $3 \mathrm{ml}$ of milk after 1 year. Hence, this treatment seemed to be very effective for achieving unresponsiveness to $3 \mathrm{ml}$ of milk. Furthermore, 4 of these 7 subjects were actually able to consume $25 \mathrm{ml}$ of milk, indicating that for the improvement of food allergies and for tolerating larger amounts, continuing the intake of small amounts can be as effective as the intake of large amounts, and increasing milk intake is not always necessary to acquire unresponsiveness to higher doses.

\section{Safety of OIT}

Adverse allergic reactions were more frequent in the hospital than at home; however, the doses administered at the hospital were at the beginning of the treatment and were continually being increased, so it is not surprising that the incidence of adverse reactions was higher [24]. Nonetheless, the induced symptoms in the hospital and 
at home were minimal compared to those seen conventionally [12], and severe symptoms were also minimal, being similar to those with sublingual immunotherapy [14]. Our study suggests that low-dose-induction OIT may be a relatively safe treatment method, likely owing to the fact that we did not encourage increasing the doses to over $3 \mathrm{ml}$, thereby reducing the risk of symptom emergence while increasing the dose, which some studies have reported as a risk factor for provoking symptoms [7, 12, 25].

\section{Immunological Changes}

Despite the low levels of intake, the casein-specific IgE levels were significantly reduced. Furthermore, $\mathrm{IgG}_{4}$ has been reported to be related to tolerance induction $[9,11$, $14]$. We found that the casein-specific $\operatorname{IgG}_{4}$ levels were significantly elevated, and an immunological change may have been induced. Thus, despite the low intake, a small amount of milk may help reduce, or even cure, milk allergies.

In this study, responders to OIT had significant lower milk-specific IgE at 6 months, but other significant immunological differences were not seen, possibly as a result of the small sample size. The mechanism of tolerance in low-dose-induction OIT is still unknown, and so larger studies are needed.

\section{Limitations}

There are several limitations to this study. First, the sample size was relatively small. Responders to OIT displayed no significant immunological differences except milk-specific IgE at 6 months. However, it is likely that the inclusion of more cases might detect statistically significant changes in other immunological parameters as well. Second, this was an open-label rather than a blinded trial, so double-blinded trials may be needed in the future to confirm our findings. Lastly, although the control group, by considering the family's choice, was similar to the OIT group, the groups were not randomized, and randomized studies will be needed.

\section{Conclusion}

In this study, involving a high-risk population known to have had severe reactions to very low amounts of milk, low-dose-induction OIT was demonstrated to represent a relatively safe and effective treatment method. Despite the low levels of intake, an immunological change appeared to be induced, and continuing the intake of small amounts seemed effective for tolerating larger amounts. Moreover, this treatment may help reduce symptoms against accidental exposure to small amounts of milk products. Accordingly, it can be hypothesized that it will help to improve the quality of life of subjects considerably. We await a prospective, randomized, control trial with a larger sample size in the future.

\section{Acknowledgements}

We thank all of the pediatricians, nutritionists, and nurses who participated in patient recruitment and data collection at Sagamihara National Hospital. This study was supported by the Health and Labor Sciences Research Grants of the Research on Allergic Disease and Immunology from the Ministry of Health, Labor and Welfare.

\section{Disclosure Statement}

There is no conflict of interest to declare.

\section{References}

1 Boyce JA, Assa'ad A, Burks AW, et al: Guidelines for the diagnosis and management of food allergy in the United States: report of the NIAID-sponsored expert panel. J Allergy Clin Immunol 2010;126(6 suppl):S1-S58.

2 Muraro A, Werfel T, Hoffmann-Sommergruber K, et al: EAACI Food Allergy and Anaphylaxis Guidelines: diagnosis and management of food allergy. Allergy 2014;69:10081025.
3 Lifschitz C, Szajewska H: Cow's milk allergy: evidence-based diagnosis and management for the practitioner. Eur J Pediatr 2015;174: 141-150.

4 Elizur A, Rajuan N, Goldberg MR, Leshno M, Cohen A, Katz Y: Natural course and risk factors for persistence of IgE-mediated cow's milk allergy. J Pediatr 2012;161:482-487.e1.
5 Wood RA, Sicherer SH, Vickery BP, Jones SM, Liu AH, Fleischer DM, Henning AK, Mayer L, Burks AW, Grishin A, Stablein D, Sampson HA: The natural history of milk allergy in an observational cohort. J Allergy Clin Immunol 2013;131:805-812.

6 Sackesen C, Assa'ad A, Baena-Cagnani C, Ebisawa M, Fiocchi A, Heine RG, Von Berg A, Kalayci O: Cow's milk allergy as a global challenge. Curr Opin Allergy Clin Immunol 2011; 11:243-248. 
7 Yeung JP, Kloda LA, McDevitt J, Ben-Shoshan M, Alizadehfar R: Oral immunotherapy for milk allergy. Cochrane Database Syst Rev 2012;11:CD009542.

8 Brożek JL, Terracciano L, Hsu J, Kreis J, Compalati E, Santesso N, Fiocchi A, Schünemann HJ: Oral immunotherapy for IgE-mediated cow's milk allergy: a systematic review and meta-analysis. Clin Exp Allergy 2012;42:363374.

9 Sato S, Yanagida N, Ogura K, Imai T, Utsunomiya T, Iikura K, Goto M, Asaumi T, Okada Y, Koike Y, Syukuya A, Ebisawa M: Clinical studies in oral allergen-specific immunotherapy: differences among allergens. Int Arch Allergy Immunol 2014;164:1-9.

10 Keet CA, Seopaul S, Knorr S, Narisety S, Skripak J, Wood RA: Long-term follow-up of oral immunotherapy for cow's milk allergy. J Allergy Clin Immunol 2013;132:737-739.e6.

11 Savilahti EM, Savilahti E: Development of natural tolerance and induced desensitization in cow's milk allergy. Pediatr Allergy Immunol 2013;24:114-121.

12 Longo G, Barbi E, Berti I, Meneghetti R, Pittalis A, Ronfani L, Ventura A: Specific oral tolerance induction in children with very severe cow's milk-induced reactions. J Allergy Clin Immunol 2008;121:343-347.
13 Yanagida N, Minoura T, Kitaoka S: Butter tolerance in children allergic to cow's milk. Allergy Asthma Immunol Res 2015;7:186-189.

14 Wang J, Sampson HA: Oral and sublingual immunotherapy for food allergy. Asian Pac J Allergy Immunol 2013;31:198-209.

15 Keet CA, Frischmeyer-Guerrerio PA, Thyagarajan A, Schroeder JT, Hamilton RG, Boden S, Steele P, Driggers S, Burks AW, Wood RA: The safety and efficacy of sublingual and oral immunotherapy for milk allergy. J Allergy Clin Immunol 2012;129:448-455.

16 Ahrens B, Lopes de Oliveira LC, Grabenhenrich L, Schulz G, Niggemann B, Wahn U, Beyer K: Individual cow's milk allergens as prognostic markers for tolerance development? Clin Exp Allergy 2012;42:1630-1637.

17 Sicherer SH, Wood RA, Vickery BP, Jones SM, Liu AH, Fleischer DM, Dawson P, Mayer L, Burks AW, Grishin A, Stablein D, Sampson HA: The natural history of egg allergy in an observational cohort. J Allergy Clin Immunol 2014;133:492-499.

18 Costa LC, Rezende ER, Segundo GR: Growth parameters impairment in patients with food allergies. J Allergy (Cairo) 2014;2014:980735.

19 Mehta H, Ramesh M, Feuille E, Groetch M, Wang J: Growth comparison in children with and without food allergies in 2 different demographic populations. J Pediatr 2014;165: 842-848
20 Flammarion S, Santos C, Guimber D, Jouannic L, Thumerelle C, Gottrand F, Deschildre A: Diet and nutritional status of children with food allergies. Pediatr Allergy Immunol 2011; 22:161-165.

21 Skripak JM, Matsui EC, Mudd K, Wood RA: The natural history of IgE-mediated cow's milk allergy. J Allergy Clin Immunol 2007; 120:1172-1177.

22 Lomas JM, Bingemann TA: Clinical predictors for favorable outcomes in an oral immunotherapy program for IgE-mediated cow's milk allergy. Pediatrics 2014; 134(suppl 3):S156.

23 Levy MB, Elizur A, Goldberg MR, Nachshon L, Katz Y: Clinical predictors for favorable outcomes in an oral immunotherapy program for IgE-mediated cow's milk allergy. Ann Allergy Asthma Immunol 2014;112:5863.e1.

24 Barbi E, Longo G, Berti I, Neri E, Saccari A, Rubert L, Matarazzo L, Montico M, Ventura A: Adverse effects during specific oral tolerance induction: in-hospital 'rush' phase. Eur Ann Allergy Clin Immunol 2012;44:18-25.

25 Casale TB, Stokes JR: Immunotherapy: what lies beyond. J Allergy Clin Immunol 2014; 133:612-619. 